\title{
Overexpression of a Water-Forming NADH Oxidase Improves the Metabolism and Stress Tolerance of Saccharomyces cerevisiae in Aerobic Fermentation
}

\author{
Xinchi Shi1,2, Yanan Zou1,2, Yong Chen ${ }^{1,2,3 *}$, Cheng Zheng ${ }^{1,2}$ and Hanjie Ying ${ }^{1,2,3 *}$ \\ ' National Engineering Research Center for Biotechnology, College of Biotechnology and Pharmaceutical Engineering, \\ Nanjing Tech University, Nanjing, China, ${ }^{2}$ State Key Laboratory of Materials-Oriented Chemical Engineering, College of \\ Biotechnology and Pharmaceutical Engineering, Nanjing Tech University, Nanjing, China, ${ }^{3}$ Jiangsu National Synergistic \\ Innovation Center for Advanced Materials, Nanjing, China
}

Redox homeostasis is fundamental to the maintenance of metabolism. Redox imbalance can cause oxidative stress, which affects metabolism and growth. Waterforming NADH oxidase regulates the redox balance by oxidizing cytosolic NADH to $\mathrm{NAD}^{+}$, which relieves cytosolic $\mathrm{NADH}$ accumulation through rapid glucose consumption in Saccharomyces cerevisiae, thus decreasing the production of the by product glycerol in industrial ethanol production. Here, we studied the effects of overexpression of a water-forming $\mathrm{NADH}$ oxidase from Lactococcus lactis on the stress response of S. cerevisiae in aerobic batch fermentation, and we constructed an interaction network of transcriptional regulation and metabolic networks to study the effects of and mechanisms underlying NADH oxidase regulation. The oxidase-overexpressing strain (NOX) showed increased glucose consumption, growth, and ethanol production, while glycerol production was remarkably lower. Glucose was exhausted by NOX at $26 \mathrm{~h}$, while $18.92 \pm 0.94 \mathrm{~g} / \mathrm{L}$ residual glucose was left in the fermentation broth of the control strain (CON) at this time point. At $29.5 \mathrm{~h}$, the ethanol concentration for NOX peaked at $35.25 \pm 1.76 \mathrm{~g} / \mathrm{L}$, which was $14.37 \%$ higher than that for CON (30.82 $\pm 1.54 \mathrm{~g} / \mathrm{L})$. Gene expression involved in the synthesis of thiamine, which is associated with stress responses in various organisms, was increased in NOX. The transcription factor HAP4 was significantly upregulated in NOX at the late-exponential phase, indicating a diauxic shift in response to starvation. The apoptosis-inducing factor Nuc1 was downregulated while the transcription factor Sok2, which regulates the production of the small signaling molecule ammonia, was upregulated at the late-exponential phase, benefiting young cells on the rim. Reactive oxygen species production was decreased by $10 \%$ in NOX, supporting a decrease in apoptosis. The HOG pathway was not activated, although the osmotic stress was truly higher, indicating improved osmotolerance. Thus, the $\mathrm{NADH}$ oxidase can regulate the metabolism during aerobic fermentation in S. cerevisiae, thereby protecting cells against several stresses. Our findings indicate its suitability for use in industrial processes.

Keywords: Saccharomyces cerevisiae, NADH oxidase, stress response, transcriptome analysis, thiamine synthesis, global transcriptional factor HAP4, apoptosis, osmotolerance 


\section{INTRODUCTION}

Metabolic engineering has generally focused on the directed improvement of cellular properties through the modification of specific biochemical reactions or the introduction of new ones (Stephanopoulos, 1999). However, researchers are beginning to realize that metabolic networks cannot be simply represented as assemblies of genes and proteins with functional properties plainly emerging from their interconnections (Nielsen, 2003). Instead, the potential relationship between the structure and functionality of metabolites and cofactors in a metabolic network needs to be investigated before one can proceed to modifying an existing or constructing a new network (Jeong et al., 2000; Monk et al., 2013).

Cofactors supply Gibbs free energy, redox equivalents, and functional groups in metabolic networks (Zhao and van der Donk, 2003; Liu and Wang, 2007). They generally are the most tightly connected nodes of a network. The intracellular redox potential is primarily determined by the NADH/NAD ${ }^{+}$ ratio and to a lesser extent by the $\mathrm{NADPH} / \mathrm{NADP}^{+}$ratio (Vemuri et al., 2007). In Saccharomyces cerevisiae, these cofactors are involved in $\geq 200$ reactions spanning a wide range of cellular functions (Doerks et al., 2002). Because NADH is a highly connected metabolite in the metabolic network (Doerks et al., 2002), any change in the $\mathrm{NADH} / \mathrm{NAD}^{+}$ratio leads to widespread metabolic changes (Nielsen, 2003). Overexpression of the water-forming NADH oxidase encoded by the noxE gene from Lactococcus lactis regulated the intracellular redox balance in S. cerevisiae by relieving cytosolic NADH accumulation, resulting in substantially lower glycerol synthesis (Heux et al., 2006; Hou et al., 2009, 2010). Heterologous expression likely induces a wide-ranging response instead of affecting a specific metabolic reaction, with network effects centering on the altered reaction (Holm et al., 2010). Kim et al. (2015) found that NADH oxidase overexpression increases 2,3-butanediol production in Pdc-deficient S. cerevisiae. Hou et al. (2014) showed that it decreased xylitol and glycerol production in xylose-metabolizing yeast. Moreover, our previous study demonstrated increased cell growth and ethanol production, and decreased glycerol production in anaerobic conditions upon overexpression of NADH oxidase in S. cerevisiae (Shi et al., 2016).

Thiamine is another important metabolic cofactor, which can alleviate redox stress, in S. cerevisiae (Alff-Tuomala et al., 2016). The active form of thiamine is ThdP (Hohmann and Meacock, 1998). HET is a precursor of thiamine, and ADT, the conversion of which is catalyzed by Thi4, is the precursor of HET (Faou and Tropschug, 2004), and $\mathrm{NAD}^{+}$is the source of the carbohydrate precursor of ADT (Jurgenson et al., 2006; Chatterjee et al., 2007). Since overexpression of NADH oxidase increases the regeneration of $\mathrm{NAD}^{+}$, it might also regulate the

\footnotetext{
Abbreviations: ADT, adenosine diphospho-5-( $\beta$-ethyl)-4-methylthiazole-2carboxylic acid; CON, Saccharomyces cerevisiae BY4741 containing the empty plasmid pYX212; HET, 5-hydroxyethyl-4-methylthiazole; NOX, S. cerevisiae BY4741 overexpressing the water-forming NADH oxidase encoded by noxE; ROS, reactive oxygen species; ThdP, thiamine diphosphate.
}

synthesis of ADT, thus influencing the synthesis and metabolism of thiamine. This point of view has not been investigated to date.

A study by Hou et al. (2009) revealed increased glucose consumption in an NADH oxidase-overexpressing strain, suggesting that it would confront with starvation stress when glucose was depleted while the normal strain would not. Diauxic shift is a type of starvation stress response that occurs when yeast cells have consumed all glucose fermentatively and resort to oxidative catabolism of the remaining ethanol (Lascaris et al., 2002), indicating that the NADH oxidase-overexpressing strain underwent the diauxic shift earlier than the control strain. Overexpression of the global transcriptional factor HAP4 provokes changes that also occur during the diauxic shift (Blom et al., 2000; Lascaris et al., 2002). To our knowledge, a relationship between NADH oxidase and HAP4 has not been reported as so far.

$\mathrm{Xu}$ et al. (2010) found that overexpression of a heterologous water-forming NADH oxidase in Torulopsis glabrata resulted in decreased ROS production and protected the yeast cells from ROS-induced damage. In addition, it improved the osmotolerance of the cells (Blom et al., 2000; Xu et al., 2010). As NADH oxidase overexpression in S. cerevisiae might improve the osmotolerance of cells under high osmotic stress, lack of induction of the HOG pathway-one of the best-studied classical MAPK pathways-might suppress or delay apoptosis. However, this has not been reported to date.

The construction of a global interaction network, including transcriptional regulation and metabolic networks, to integrate data from transcription profiles and the metabolite levels (Holm et al., 2010), is an efficient method to study the mechanisms underlying some specific regulation (Vemuri et al., 2007; Celton et al., 2012) or changes in growth conditions (Li et al., 2015). To better understand the mechanisms of NADH oxidase regulation, comparative RNA-seq analysis of a S. cerevisiae control strain $(\mathrm{CON})$ and NADH oxidase strain (NOX) was conducted, with a focus on the stress response.

\section{MATERIALS AND METHODS}

\section{Construction of the Yeast Strains}

The strains and plasmids used in this study are listed in Table 1. The noxE (GenBank Accession No. AM406671) gene encoding the water-forming $\mathrm{NADH}$ oxidase from L. lactis was PCR-amplified with primers Nox-F, 5'CTTGTGGGCCCAGGATCCATGAAAATCGTAGTTATCG-3', and Nox-R, 5'-ACAGGAATTCACCATGGATCCTTATTTGGCA TTCAAAGCTG-3'. Both primers have a BamHI site (underlined), and the homologous arms of the plasmid are indicated in italics in the primer sequences. PCR products were gel-purified and inserted into the BamHI site of pYX212 by using the ClonExpress ${ }^{\mathrm{TM}}$ One Step Cloning Kit (Vazyme Biotech, Co., Ltd, Nanjing, China), yielding pYX212-NOX. The plasmid was transformed into the host strain, BY4741, using G418 $(400 \mu \mathrm{g} / \mathrm{ml})$ to select a stably transfected clone, designated NOX (Table 1). As a control, CON, the host strain transfected with empty plasmid, was used. 
TABLE 1 | List of plasmids and strains used in this study.

\begin{tabular}{|c|c|c|}
\hline Plasmid/strain & Genotype & Source \\
\hline \multicolumn{3}{|l|}{ Plasmid } \\
\hline $\begin{array}{l}\text { pYX212 } \\
\text { pYX212-NOX }\end{array}$ & $\begin{array}{l}2 \mu, \text { TPI promoter, AMPR } \\
\text { pYX } 212 \text { with nox from Lactococcus lactis }\end{array}$ & $\begin{array}{l}\text { A gift from Prof. Yingjin Yuan (Tianjin University, Tianjin, China) } \\
\text { This study }\end{array}$ \\
\hline \multicolumn{3}{|l|}{ Strain } \\
\hline BY4741 & MATa;ura3;his3;leu2;met15 & A gift from Prof. Yingjin Yuan (Tianjin University, Tianjin, China) \\
\hline CON & BY4741/pYX212 & This study \\
\hline NOX & BY4741/pYX212-NOX & This study \\
\hline
\end{tabular}

\section{Media and Growth Conditions}

The strains were maintained on conventional yeast extract peptone dextrose (YPD) agar plates as described previously (Ito et al., 1983). Seed cultures for cultivation were grown at $30^{\circ} \mathrm{C}$ in 500-ml Erlenmeyer flasks containing $100 \mathrm{ml}$ complex medium A (initial pH 5.2) containing glucose $(20 \mathrm{~g} / \mathrm{L})$, tryptone $(10 \mathrm{~g} / \mathrm{L}$; Oxoid), yeast extract (5 g/L; Oxoid), and $\mathrm{NaCl}$ (9 g/L) (Barber et al., 2002) on a rotary shaker at $200 \mathrm{rpm}$. Aerobic fermentations were performed at $32^{\circ} \mathrm{C}$ in 500 -ml Erlenmeyer flasks containing $100 \mathrm{ml}$ complex medium A with $90 \mathrm{~g} / \mathrm{L}$ glucose (initial pH 5.2) on a rotary shaker at $200 \mathrm{rpm}$ after the addition of $10 \mathrm{ml}$ of OD-standardized seed cultures.

\section{Metabolite Analyses}

The cell density was measured using a BioMate ${ }^{\mathrm{TM}} 3$ spectrophotometer (Thermo Scientific, Waltham, MA, USA) at $600 \mathrm{~nm}$. A small volume $(5 \mathrm{ml})$ of culture was centrifuged at $4,000 \times g$ for $10 \mathrm{~min}$. The supernatants were used to determine the concentrations of glucose, ethanol, and glycerol. The glucose and glycerol concentrations were measured by high performance liquid chromatography (Agilent 1100 series; Hewlett-Packard, Palo Alto, CA, USA) with a refractive index detector, using a Benson BP-100 $\mathrm{Pb}^{++}$column $(300 \mathrm{~mm} \times 7.8 \mathrm{~mm}$; Benson Polymeric, Inc., Sparks, NV, USA). Ultrapure water was used as the mobile phase at a flow rate of $0.4 \mathrm{ml} / \mathrm{min}$ and $80^{\circ} \mathrm{C}$. The ethanol concentration was analyzed by gas chromatography using an Agilent HP-INNOWAX column $(60 \mathrm{~m} \times 250 \mu \mathrm{m} \times 0.5 \mu \mathrm{m})$ with a flame ionization detector as described previously (Chen et al., 2014).

\section{Enzyme Activity}

For the determination of NOX activity, $S$. cerevisiae cells were collected by centrifugation at $6,000 \times g$ at room temperature. The pellet was resuspended in $50 \mathrm{mM}$ phosphate buffer $(\mathrm{pH}$ 7.0). After adding $0.2 \mathrm{~g}$ of glass beads (I.D. $0.5 \mathrm{~mm}$, Biospec, Bartlesville, OK, USA) into the cell suspension, the mixture was vortexed vigorously for $1 \mathrm{~min}$ and cooled for $4 \mathrm{~min}$ three times (Lee et al., 2012). After centrifugation for $3 \mathrm{~min}$ at $12,000 \times g$ at $4^{\circ} \mathrm{C}$, the supernatant crude protein extract was used for the enzyme assay. Total NADH oxidation activity was assayed spectrophotometrically following the method of Vemuri et al. (2007). Protein was quantified by the Bradford method using BSA as a standard.

\section{Quantification of Intracellular NAD(P)H/NAD(P)}

The intracellular concentration of $\mathrm{NAD}(\mathrm{P}) \mathrm{H}$ was determined by the enzyme cycling method of Liu et al. (2013) with modifications. Generally, two tubes of $1-\mathrm{ml}$ sample were taken and cells were collected and dissolved in $0.5 \mathrm{ml} 0.1 \mathrm{M} \mathrm{NaOH}$ [to assay $\mathrm{NAD}(\mathrm{P}) \mathrm{H}$ ] and $0.5 \mathrm{ml} 0.1 \mathrm{M} \mathrm{HCl}$ [to assay $\mathrm{NAD}(\mathrm{P})$ ], respectively. The cell lysate was heated at $50^{\circ} \mathrm{C}$ for $10 \mathrm{~min}$, cooled to $0^{\circ} \mathrm{C}$, and centrifuged at $10,000 \times g$ for $10 \mathrm{~min}$. The supernatant was used for measurement. One hundred microliters of Tris-HCl (1 M, pH 7.8), $100 \mu \mathrm{L} 4.2 \mathrm{mM}$ MTT, $150 \mu \mathrm{L}$ 16.6 $\mathrm{mM}$ PES, and $100 \mu \mathrm{L}$ ethanol for the determination of $\mathrm{NAD}(\mathrm{H})$ or $100 \mu \mathrm{L} 60 \mathrm{mM}$ glucose 6-phosphate for the determination of $\operatorname{NADP}(\mathrm{H})$, were sequentially added to a test tube and kept at $37^{\circ} \mathrm{C}$ for $5 \mathrm{~min}$ in the dark. $\mathrm{ddH}_{2} \mathrm{O}$ and an appropriate amount of supernatant $(75 \mu \mathrm{L}$ in total) were added to 96-well plates. The plates were transferred into a Multimode Detection Platform (SpectraMax Paradigm; Molecular Devices, Sunnyvale, CA, USA) and preheated at $37^{\circ} \mathrm{C}$ for $5 \mathrm{~min}$. Ten microliters of alcohol dehydrogenase $[1.5$ units $/ \mu \mathrm{L}$, for $\mathrm{NAD}(\mathrm{H})$ ] or glucose 6-phosphate dehydrogenase [70 units $/ \mathrm{ml}$, for $\mathrm{NADP}(\mathrm{H})]$ were added to the mixture, and $46 \mu \mathrm{L}$ of the mixture was added to the 96-well plates to start the reaction. The absorbance at $570 \mathrm{~nm}$ was determined. $\mathrm{NADH}$ was measured for 10 min with 2-min intervals, and NADPH, NADP, and NAD were measured for $30 \mathrm{~min}$ with 5-min intervals.

\section{Harvest of Cells and RNA Isolation}

Cells of the CON and NOX strains were collected during three different growth stages - the beginning $(8 \mathrm{~h})$, the middle $(22 \mathrm{~h})$, and the end of the exponential phase (29.5 h)-by centrifugation $\left(5,000 \times g, 5 \mathrm{~min}, 4^{\circ} \mathrm{C}\right)$ and washed twice in PBS (8 g/L NaCl, $0.2 \mathrm{~g} / \mathrm{L} \mathrm{KCl}, 1.44 \mathrm{~g} / \mathrm{L} \mathrm{Na} \mathrm{HPO}_{4}, 0.24 \mathrm{~g} / \mathrm{L}$ $\mathrm{KH}_{2} \mathrm{PO}_{4}, \mathrm{pH}$ 7.4; Li et al., 2015). The cell pellets were immediately frozen in liquid nitrogen and stored at $-80^{\circ} \mathrm{C}$. Three samples of the same stage were pooled and homogenized, and total RNA was extracted to prepare staged samples for transcript analyses as described previously (Irie and Kuratani, 2011).

\section{RNA-seq Analysis}

RNA-seq analysis was conducted as described in detail by Li et al. (2015). To improve the reliability of data in each 
developmental stage, we took $2 \mathrm{G}$ of sequencing data (Cao et al., 2005). Differential expression between two experimental conditions was detected by carrying out a modified $t$-test, with a significance threshold of $P<0.05$. Only genes displaying a fold-change in the expression level of $\geq 2$ (positive or negative), which corresponds with an absolute $\log _{2}$ ratio value $\geq 1$, were considered to be significantly differentially regulated. Because this analysis tests 1000 s of hypotheses simultaneously (in determining whether given genes are differentially expressed between two groups), corrections for false positives (type I errors) and false negatives (type II errors) were performed using the false discovery rate (FDR) method (Benjamini and Yekutieli, 2001). An FDR $\leq 0.001$ and absolute value of $\log _{2}$ ratio $\geq 1$ were set as criteria for assessing the significance of differential gene expression. Gene ontology (GO) enrichment analysis and pathway enrichment analysis were performed as in $\mathrm{Li}$ et al. (2015). The Illumina sequencing data were deposited into the NCBI database under the accession number SRP072476.

\section{ROS Analysis}

Reactive oxygen species was measured following the method of Xu et al. (2010). A flow cytometer (BD FACS Calibur, Becton, Dickinson and Company, USA) was used to detect the fluorescence intensity of the cell suspension. Cells of CON and NOX strains were collected at $22 \mathrm{~h}$ (the mid-exponential phase) and $34 \mathrm{~h}$ (the stationary phase). ROS production was expressed as a ratio relative to that in CON cells collected at $22 \mathrm{~h}$.

\section{Osmolarity Determination}

Osmolarity was measured using an automatic cryoscopic osmometer (OSMOMAT 030, GONOTEC GmbH, Berlin, Germany).

\section{Quantitative Reverse Transcription (qRT)-PCR Analysis}

RNA was isolated from cells as described previously (Li et al., 2015). Reverse transcription was performed using the AMV First Strand cDNA Synthesis Kit (Sangon Biotech, Shanghai, China) according to the manufacturer's instructions. Primer Express software was used for primer design. The analyzed genes and primers used in the analysis are listed in Table 2. qRT-PCR assays were performed with the SYBR Green PCR Master Mix (Applied Biosystems, Foster City, CA, USA) on a StepOnePlus RealTime PCR System according to the manufacturer's instructions. Three technical replicates were included for each sample. Gene transcript levels were determined according to the $2^{-\Delta \Delta C t}$ method, using ACT1 (Yuan and Ching, 2015) as a reference gene for normalizing the gene expression levels. To verify qRT-PCR data, standard deviation values were calculated using Microsoft Excel (Microsoft Corporation, Redmond, WA, USA) and were used to evaluate the repeatability and the reliability of the data.

\section{RESULTS AND DISCUSSION}

\section{NADH Oxidase Overexpression Improves Aerobic Glucose Fermentation}

Batch culture growth of CON and NOX strains in aerobic condition was compared (Figure 1). The glucose consumption and cell growth rate of NOX were higher than those of CON. Glucose was exhausted at $26 \mathrm{~h}$ by NOX while $18.92 \pm 0.94 \mathrm{~g} / \mathrm{L}$ residual glucose remained in the $\mathrm{CON}$ culture at this time point. Additionally, after $29.5 \mathrm{~h}$ of fermentation, the concentration of ethanol produced by NOX peaked at $35.25 \pm 1.76 \mathrm{~g} / \mathrm{L}$, which was $14.37 \%$ higher than that of $\operatorname{CON}(30.82 \pm 1.54 \mathrm{~g} / \mathrm{L})$ at this time point. Vemuri et al. (2007) reported an ethanol yield of $0.26 \mathrm{~g} / \mathrm{g}$, i.e., $10.4 \mathrm{~g} / \mathrm{L}$, in aerobic batch fermentation of S. cerevisiae overexpressing a Streptococcus pneumoniae NADH oxidase gene. The remarkable increase obtained in our study indicates the potential benefit of our strain for industrial ethanol production. Glycerol production was remarkably lower in NOX,

\begin{tabular}{|c|c|c|}
\hline $\begin{array}{l}\text { Gene } \\
\text { ID }\end{array}$ & Gene name & Primer sequences \\
\hline YFL039C & $\begin{array}{l}\text { ACT1 } \\
\text { (reference gene) }\end{array}$ & $\begin{array}{l}\text { F: TGGATTCCGGTGATGGTGTT } \\
\text { R: TGGCGTGAGGTAGAGAGAAACC }\end{array}$ \\
\hline L196579 & noxE & $\begin{array}{l}\text { F: TCAAAAATGGCGCAATCAAG } \\
\text { R: CCGCGTAAACATCTGGATCA }\end{array}$ \\
\hline YJR158W & $H x+16$ & $\begin{array}{l}\text { F: TाTGAGCAACGTGCGTATGG } \\
\text { R: CGCCAATGGAACATCCTACA }\end{array}$ \\
\hline YDR343C & HXT6 & $\begin{array}{l}\text { F: CGCTGCTATTGCAGAGCAAAC } \\
\text { R: CGAGTGGGAGGCTGAGTCA }\end{array}$ \\
\hline YGR144W & THI4 & $\begin{array}{l}\text { F: TाTGCCGTाTCTGACGTGATT } \\
\text { R: GCGGCGGATAAACCTGAA }\end{array}$ \\
\hline YFL058W & THI5 & $\begin{array}{l}\text { F: GGTTACTTCAAGGAGCAAGGTCTAGA } \\
\text { R: CAGTGACATCGGAAGGATTGG }\end{array}$ \\
\hline YJR156C & THI11 & $\begin{array}{l}\text { F: CAAGAAGGCAACCGACTACGT } \\
\text { R: GAGGCTTGAAGTCGATGTATTCTाT }\end{array}$ \\
\hline YNL332W & THI12 & $\begin{array}{l}\text { F: GGTTACTTCAAGGAGCAAGGTCTAGA } \\
\text { R: CAGTGACATCGGAAGGATTGG }\end{array}$ \\
\hline YDL244W & THI13 & $\begin{array}{l}\text { F: CAAGAAGGCAACCGACTACGT } \\
\text { R: GAGGCTTGAAGTCGATGTATTCTाT }\end{array}$ \\
\hline YKL109W & Hap4 & $\begin{array}{l}\text { F: TGTACCGATCGCCCCAAATA } \\
\text { R: TGCCATCGTITTCGAATTCC }\end{array}$ \\
\hline YLR113W & Hog 1 & $\begin{array}{l}\text { F: GGGCATTGGGTTGGTITG } \\
\text { R: TTAATGGCAACTGGCTGAGATG }\end{array}$ \\
\hline YKL043W & Sok2 & $\begin{array}{l}\text { F: CGAAACTCCAAACGCATATGC } \\
\text { R: AGCCTGAGTTGGCGACGTA }\end{array}$ \\
\hline YKL062W & MSN4 & $\begin{array}{l}\text { F: CGGCATTCGACAATAACGTAGA } \\
\text { R: GATCCTGAGCCGGAGATGAC }\end{array}$ \\
\hline YJL208C & NUC1 & $\begin{array}{l}\text { F: TCGATCCTTCCGGGTTCTT } \\
\text { R: CGCGGTTCTGCAGATCATG }\end{array}$ \\
\hline YBR240C & THI2 & $\begin{array}{l}\text { F: CGATGTCGTCAGCAGAGGAA } \\
\text { R: TCTTCTGGCGGCGATGA }\end{array}$ \\
\hline YDL022W & GPD1 & $\begin{array}{l}\text { F: TCAATIIIGCCCCGTATCTG } \\
\text { R: GATAGCTCTGACGTGTGAATCAACA }\end{array}$ \\
\hline YHL032C & GUT1 & $\begin{array}{l}\text { F: GCCCCAGCTCGTGAAACA } \\
\text { R: GGGCTITCCGCTGGTाT }\end{array}$ \\
\hline
\end{tabular}




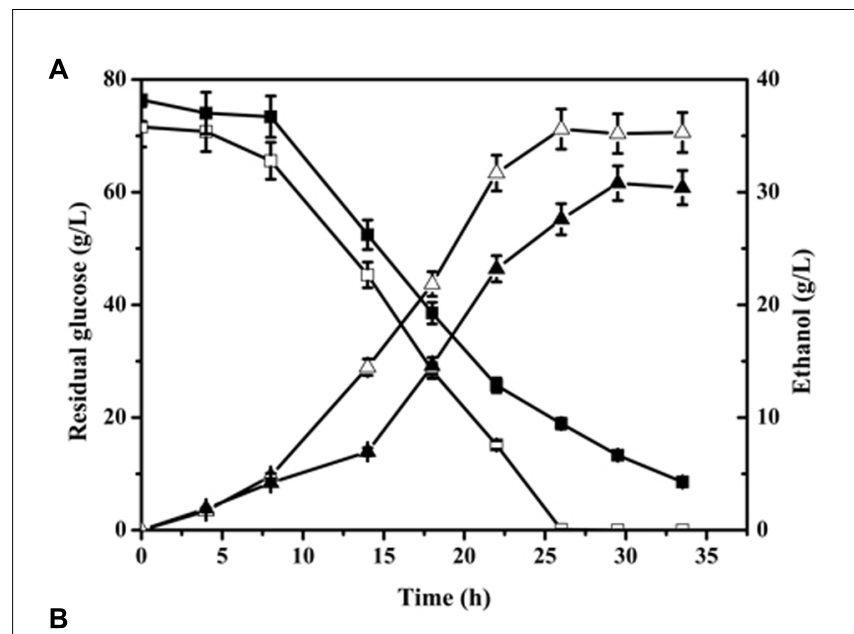

B

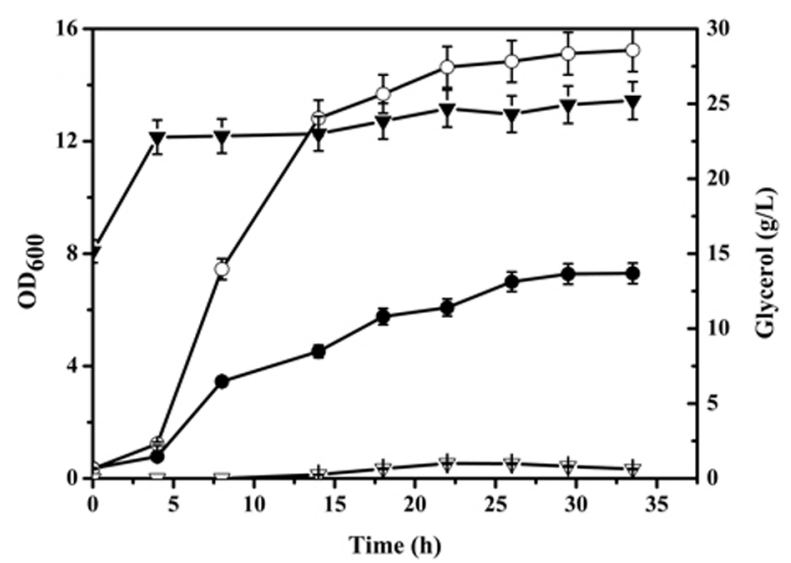

FIGURE 1 | Time profile of batch fermentation by CON and NOX. (A) $\boldsymbol{\Delta} \Delta$ represent the time profile of batch ethanol fermentation; $\square \square$, residual glucose; (B) $\bullet \circ, \mathrm{OD}_{600} ; \mathbf{\nabla} \nabla$, glycerol fermentation. Solid symbols, $\mathrm{CON}$; open symbols, NOX.

in accordance with previous reports of increased assimilation of $\mathrm{NADH}$ in the cytosol by $\mathrm{NADH}$ oxidase, leading to a reduction in glycerol production (Heux et al., 2006; Vemuri et al., 2007; Hou et al., 2009). The glycerol concentration of NOX remained under $1 \mathrm{~g} / \mathrm{L}$ in both the seed cultures and aerobic fermentation processes. CON produced a large amount of glycerol in the seed culture and in the lag phase of fermentation; more than $7 \mathrm{~g} / \mathrm{L}$ glycerol was produced within $4 \mathrm{~h}$, after which production stably increased. As NOX consumed glucose much faster, it seemed that the $\mathrm{NADH}$ oxidase also increased the demand of $\mathrm{NADH}$ in aerobic condition since the glycolysis pathway is the main pathway to generate NADH. NADH homeostasis in response to the increased NADH demand was achieved by the regulation of the glycolysis pathway, which was in accordance with a previous report on the NADPH oxidation system (Celton et al., 2012).

In the batch fermentation, the concentrations of the intracellular cofactors were measured at 26, 30, and $34 \mathrm{~h}$. The $\mathrm{NADH} / \mathrm{NAD}^{+}$ratio of NOX was higher than that of $\mathrm{CON}$ at all three time points, while the $\mathrm{NADPH} / \mathrm{NADP}^{+}$ratios were similar between the two strains (Table 3 ). The $\mathrm{NADH} / \mathrm{NAD}^{+}$ratios were not consistent with those in previous reports. Vemuri et al. (2007) reported that under either carbon-limited or nitrogenlimited conditions, the $\mathrm{NADH} / \mathrm{NAD}^{+}$ratio was $20-50 \%$ lower for the $\mathrm{NADH}$ oxidase-overexpressing than for the control strain. These inconsistencies may be due to differences in the strains and fermentation conditions used in this and previous studies. First, the parental strains were different, which may have affected the engineered phenotypes. Second, the NADH oxidase genes were from different genomic background; we used the L. lactis gene while Vemuri et al. (2007) used a S. pneumoniae gene. Third, the fermentation conditions were different; we used complete medium in batch fermentation, while Vemuri et al. (2007) conducted aerobic fermentations under nitrogen-limited and carbon-limited chemostats. Finally, the $\mathrm{NADH} / \mathrm{NAD}^{+}$ratio likely is not only determined by the action of the NADH oxidase alone, as the heterologous expression does not affect one specific metabolic reaction.

Additionally, we have measured the $\mathrm{NADH} / \mathrm{NAD}^{+}$ratio in the recombinant $S$. cerevisiae strains under various degrees of oxygen supply. The results, which corroborate our findings, have been reported elsewhere (Shi et al., 2016). The NADH/NAD ${ }^{+}$ and $\mathrm{NADPH} \mathrm{NADP}^{+}$ratios in anaerobic and microaerobic conditions showed trends similar to those in aerobic condition; the $\mathrm{NADH} / \mathrm{NAD}^{+}$ratios of $\mathrm{NOX}$ in the three oxygen supply models were higher than those of CON.

Finally, the NADH oxidation capacity was measured. The assay for determining NADH oxidation is not specific for NADH oxidase and includes native activity that $S$. cerevisiae possesses (e.g., NADH dehydrogenases; Vemuri et al., 2007). As shown in Figure 2, NOX consistently exhibited greater NADH oxidation activity than $\mathrm{CON}$ at all three time points tested.

\section{Differential Gene Expression between CON and NOX Cells}

mRNA fractions purified from CON and NOX cells at the beginning, middle, and end of the exponential phase were analyzed to determine their respective gene expression profiles and to identify differentially expressed genes. At the early exponential phase, 5798 genes were differentially expressed in NOX vs. CON, of which 992 were significantly downregulated and 230 were significantly upregulated (Figure 3 ). In cells harvested during the mid-exponential phase, 773 genes were significantly differentially expressed in NOX vs. CON, of which 651 were significantly downregulated and 122 were significantly upregulated. At the late-exponential phase, 1621 genes were significantly downregulated and 301 genes were significantly upregulated in NOX vs. CON. Interestingly, in NOX, the number of downregulated genes at the beginning of the exponential phase was 2.32-fold higher than that of upregulated genes, and the ratio was 2.46 in the mid-exponential phase and 2.50 in the late-exponential phase, thus seemingly increasing with longer fermentation. The total number of significantly upregulated genes changed only slightly during the fermentation. However, the number of significantly downregulated genes decreased markedly from the beginning to the middle of the exponential phase and then markedly increased toward the end of this 
TABLE 3 | The NADH/NAD ${ }^{+}$ratio and NADPH/NADP ${ }^{+}$ratio of CON and the NADH oxidase-overexpressing strain NOX.

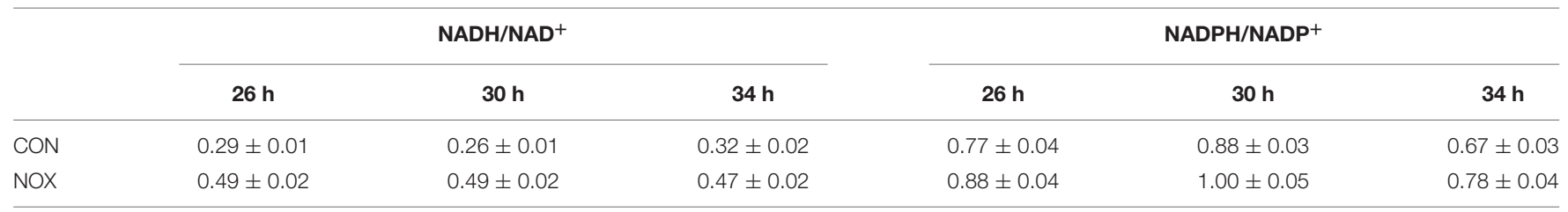

Each value is an average of three parallel replicates.

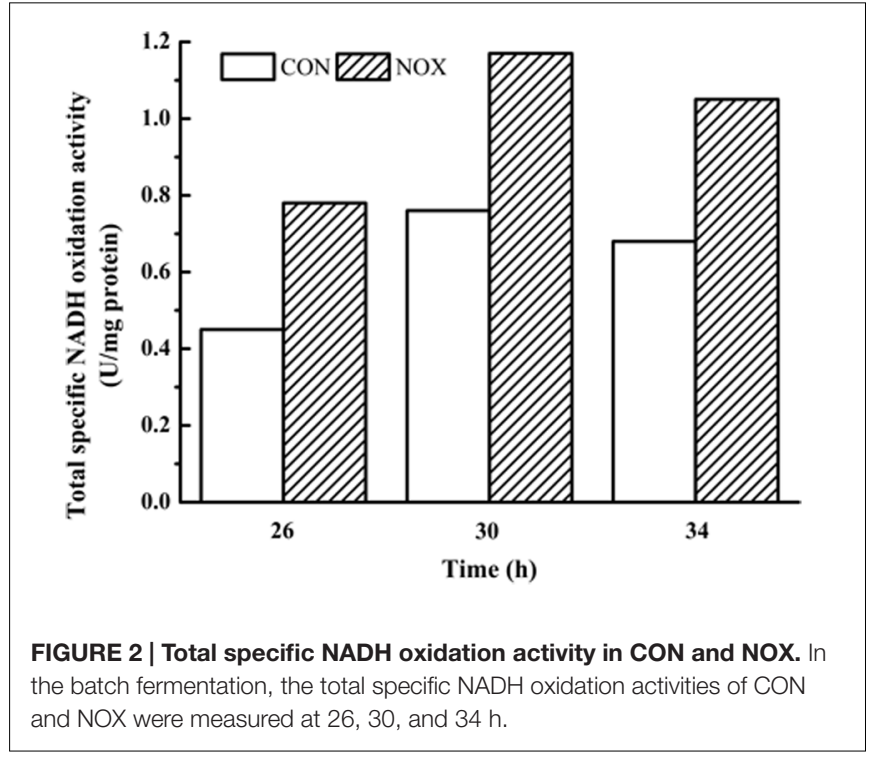

phase. Taken together over all three phases, the numbers of the significantly downregulated genes were over fourfold higher than the number of significantly upregulated genes. As shown in Figure 3, gene expression also substantially changed within NOX and CON cells during the fermentation process (columns 4-9). These comparisons indicated that a multitude of genes were differentially regulated during fermentation, as expected, and more dramatic differences were observed in NOX cells than in CON cells.

The differentially expressed genes were mapped to GO ontologies of cellular components, molecular functions, and biological processes for GO enrichment analysis (Additional files 1-3). We focused on the gene categories for which the corrected $P$-value was $\leq 0.05$ (Figure 4). Ribosome-related genes were enriched in NOX as compared to CON in both the early- and the mid-exponential phase. KEGG pathway analysis (classification criteria based on KEGG pathways: http://www.ge nome.jp/kegg/pathway.html) was used to identify significantly changed metabolic or signal transduction pathways in NOX. The KEGG pathways controlled by differentially expressed genes at different periods of cell growth are listed in Additional files 4-6. Data analysis revealed that carbohydrate, energy, amino acid, and transcription/translation pathways were enriched in NOX vs. CON during fermentation ( $Q$-values $<0.05$; Table 4). These results were in accordance with the results reported by Vemuri et al. (2007). In the early- and mid-exponential phases, only pathways related to cell growth changed significantly, while at

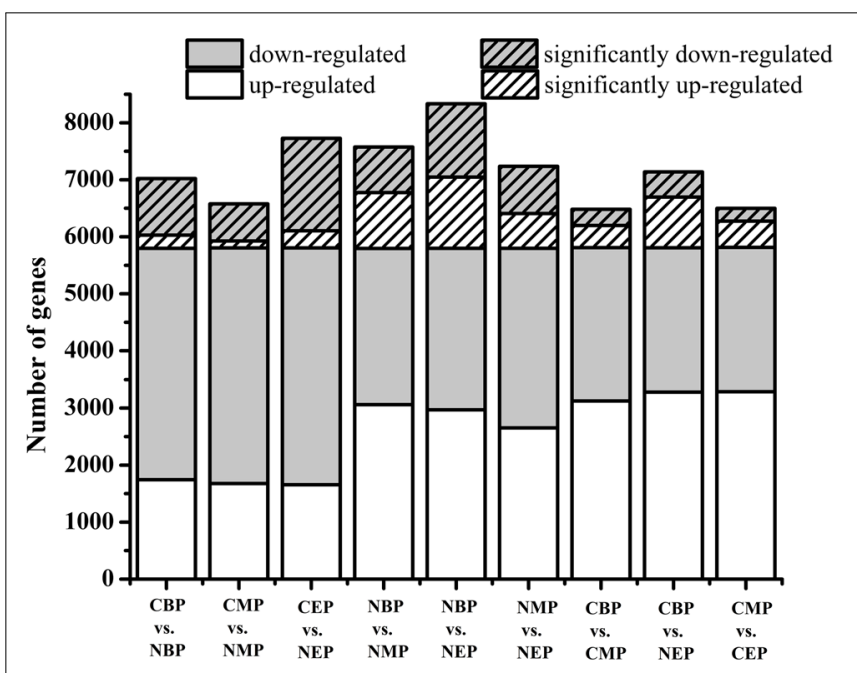

FIGURE 3 | Differences in gene expression under differing growth conditions. Hatched bars represent the number of differentially expressed genes whose expression levels were significantly different from those observed in control cells (FDR $\leq 0.001, \log _{2}$ ratio $\geq 1$ ). CBP: CON harvested in the early exponential phase; CMP: CON harvested in the mid-exponential phase; CEP: CON harvested in the late-exponential phase. NBP: NOX harvested in the early exponential phase; NMP: NOX harvested in the mid-exponential phase; NEP: NOX harvested in the late-exponential phase.

the late-exponential phase, numerous pathways were activated in NOX.

\section{Ethanol and Glycerol Metabolism are Affected at the Transcriptional Level by NADH Oxidase Overexpression}

To further analyze the transcription response of NOX vs. $\mathrm{CON}$ at the end of the exponential phase with regard to ethanol and glycerol metabolism, the transcription response was superimposed on the metabolic network with the common metabolites. The glycerol assimilation pathway, involving GUT1, was upregulated, whereas the synthesis pathway, involving GPD1, was downregulated in NOX as the glycerol synthesis pathway was activated when glycolytic NADH generation was surpassed (Figure 5). These findings were in line with the report of Vemuri et al. (2007) and were in accordance with the results of the batch fermentation, in which the accumulation of glycerol was significantly decreased in NOX. Interestingly, in contrast to the results of Vemuri et al. (2007), the conversion of acetaldehyde to 


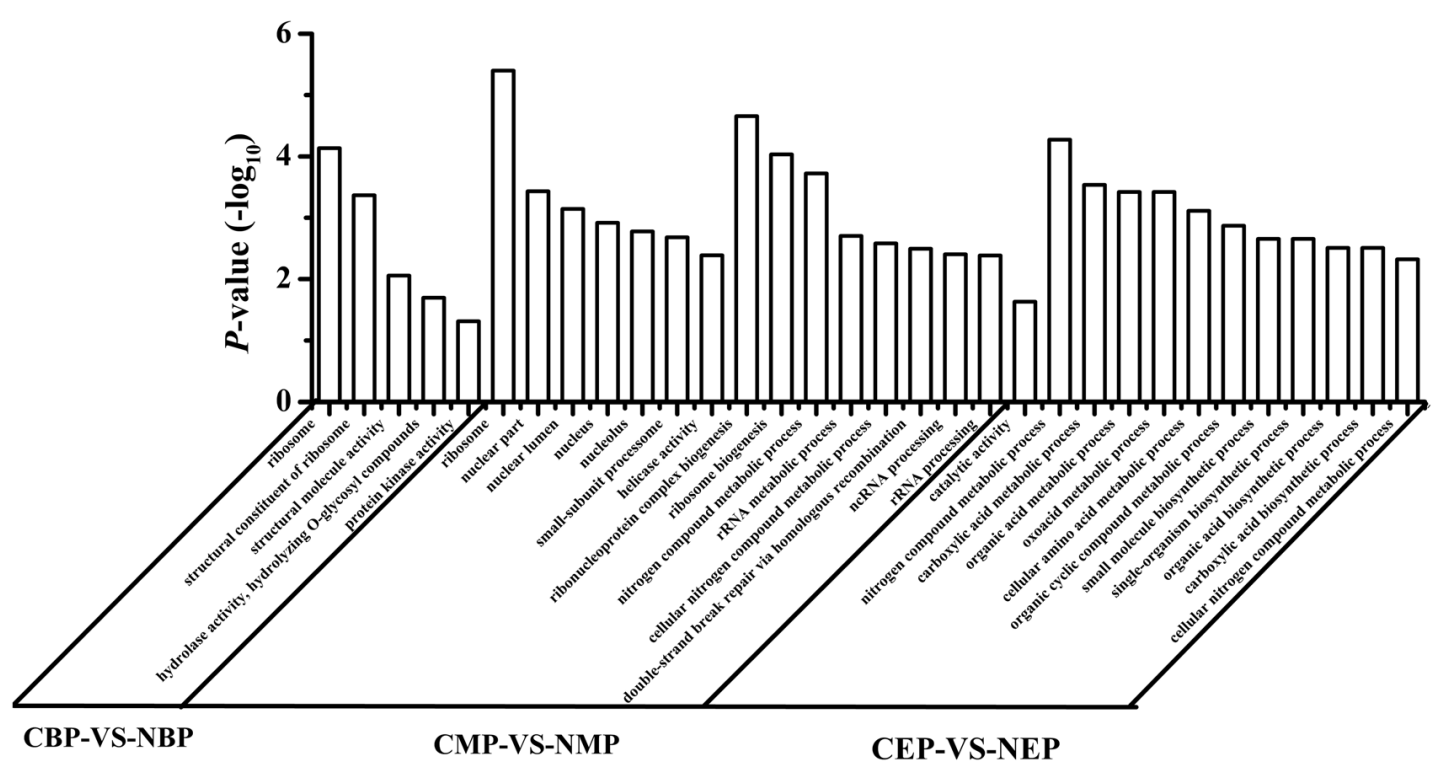

FIGURE 4 | Gene ontology (GO) category enrichment. Gene expression levels of CON cells grown for different periods were set as the background level. A corrected $P$-value $\leq 0.05$ was used as a threshold. GO terms fulfilling this condition are defined as significantly enriched GO terms for the differentially expressed genes. CBP: CON harvested in the early exponential phase; CMP: CON harvested in the mid-exponential phase; CEP: CON harvested in the late-exponential phase; NBP: NOX harvested in the early exponential phase; NMP: NOX harvested in the mid-exponential phase; NEP: NOX harvested in the late-exponential phase.

TABLE 4 | Overview of significantly enriched KEGG-pathways in NOX.

\begin{tabular}{lllll}
\hline Pathway ID Pathway & $\begin{array}{l}\text { DEGs with pathway } \\
\text { annotation (735) }\end{array}$ & $\begin{array}{l}\text { All genes with } \\
\text { pathway annotation } \\
(3778)\end{array}$ & $P$-value & $Q$-value*
\end{tabular}

CON harvested in the beginning of exponential phase (CBP) vs. NOX harvested in the beginning of exponential phase (NBP)

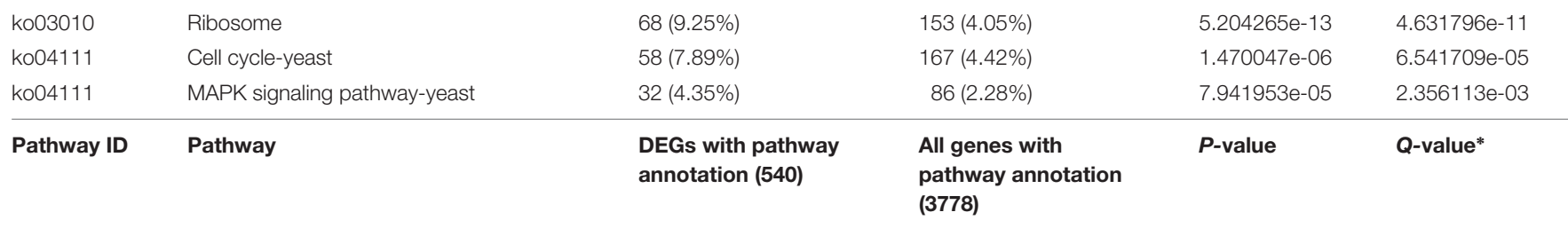

\begin{tabular}{|c|c|c|c|c|c|}
\hline \multicolumn{6}{|c|}{ CON harvested in the mid-exponential phase (CMP) vs. NOX harvested in the mid-exponential phase (NMP) } \\
\hline ko03008 & Ribosome biogenesis in eukaryotes & $31(5.74 \%)$ & $80(2.12 \%)$ & $4.245547 \mathrm{e}-08$ & 3.820992e-06 \\
\hline ko04111 & Cell cycle-yeast & $48(8.89 \%)$ & $167(4.42 \%)$ & $5.571791 e-07$ & $2.507306 e-05$ \\
\hline ko04113 & Meiosis-yeast & 39 (7.22\%) & $163(4.31 \%)$ & 0.0005482611 & $1.644783 \mathrm{e}-02$ \\
\hline Pathway ID & Pathway & $\begin{array}{l}\text { DEGs with pathway } \\
\text { annotation c4 (1314) }\end{array}$ & $\begin{array}{l}\text { All genes with } \\
\text { pathway annotation } \\
(3778)\end{array}$ & $P$-value & $Q$-value* \\
\hline
\end{tabular}

CON harvested at the end of the exponential phase (CEP) vs. NOX harvested at the end of the exponential phase (NEP)

\begin{tabular}{|c|c|c|c|c|c|}
\hline ko00640 & Propanoate metabolism & $43(3.27 \%)$ & $61(1.61 \%)$ & $1.092315 \mathrm{e}-08$ & $1.081392 \mathrm{e}-06$ \\
\hline ko00280 & Valine, leucine, and isoleucine degradation & $41(3.12 \%)$ & $59(1.56 \%)$ & $4.661189 \mathrm{e}-08$ & $1.602433 \mathrm{e}-06$ \\
\hline ko00410 & Beta-Alanine metabolism & $42(3.2 \%)$ & $61(1.61 \%)$ & $4.855858 \mathrm{e}-08$ & $1.602433 e-06$ \\
\hline ko00562 & Inositol phosphate metabolism & $43(3.27 \%)$ & $66(1.75 \%)$ & $3.855312 \mathrm{e}-07$ & $9.541897 \mathrm{e}-06$ \\
\hline ko01100 & Metabolic pathways & $349(26.56 \%)$ & $858(22.71 \%)$ & $2.526684 \mathrm{e}-05$ & $5.002834 \mathrm{e}-04$ \\
\hline ko00970 & Aminoacyl-tRNA biosynthesis & $25(1.9 \%)$ & $41(1.09 \%)$ & 0.0005149399 & $8.496508 \mathrm{e}-03$ \\
\hline ko01110 & Biosynthesis of secondary metabolites & $137(10.43 \%)$ & $319(8.44 \%)$ & 0.0009647584 & $1.322082 \mathrm{e}-02$ \\
\hline ko00330 & Arginine and proline metabolism & $22(1.67 \%)$ & $36(0.95 \%)$ & 0.001068349 & $1.322082 \mathrm{e}-02$ \\
\hline ko00240 & Pyrimidine metabolism & 42 (3.2\%) & 85 (2.25\%) & 0.00350519 & $3.855709 \mathrm{e}-02$ \\
\hline
\end{tabular}

*Pathways with $Q$-values $\leq 0.05$ were significantly enriched in differentially expressed genes (DEGs). 


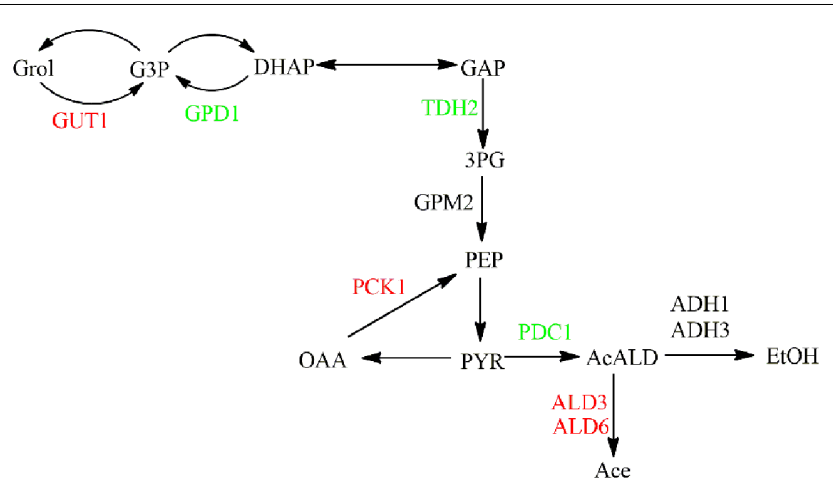

FIGURE 5 | Transcription response of strains in the late-exponential phase superimposed on ethanol and glycerol metabolism. Genes upregulated in NOX vs. CON are indicated in red, those downregulated in NOX vs. CON are indicated in green. GUT1: glycerol kinase; GPD1: glycerol-3-phosphate dehydrogenase; TDH2: glyceraldehyde-3-phosphate dehydrogenase; GPM2: 2,3-bisphosphoglycerate-dependent phosphoglycerate mutase; PCK1: phosphoenolpyruvate carboxykinase; PDC1: pyruvate decarboxylase; ALD3: aldehyde dehydrogenase; ALD6: aldehyde dehydrogenase; $\mathrm{ADH} 1$ : alcohol dehydrogenase; $\mathrm{ADH}$ 3: alcohol dehydrogenase. ethanol did not change significantly while the conversion of pyruvate to acetaldehyde was downregulated. The conversion of acetaldehyde to acetate was stimulated as previously reported (Figure 5).

According to the results of batch fermentation, the production of ethanol was improved, while in the study of Vemuri et al. (2007), it was decreased in NOX when compared with CON. These differences were reflected at the transcriptional level. In our study, the overexpression of $\mathrm{NADH}$ oxidase seemed to increase ethanol production mainly through the enhancement of glycolysis rather than through upregulation of ethanol synthesis genes. In terms of the ethanol production in NADH oxidaseoverexpressing strains, different results have been reported. Hou et al. (2009) reported that the ethanol production rate was largely unaffected by perturbation of the cytosolic NADH. Similar to the different $\mathrm{NADH} / \mathrm{NAD}^{+}$ratios in our and other studies, the differences of ethanol production and relevant transcriptional expression could be explained in several ways as mentioned above.

\section{Expression of Genes Related to Thiamine Synthesis in Response to NADH Oxidase Overexpression}

Thiamine diphosphate is an important cofactor in the metabolic pathway and the function of thiamine in stress responses has drawn much attention recently (Wolak et al., 2014). THI genes have a putative role in the biosynthesis of the enzyme cofactor ThdP (Figure 6). The four highly conserved members in S. cerevisiae, THI11, THI12, THI13, and THI5 are known as the THI5 gene family (Wightman and Meacock, 2003), which plays a putative role in the biosynthesis of the thiamin precursor hydroxymethylpyrimidine diphosphate. According to the transcriptome sequencing data, during fermentation, the

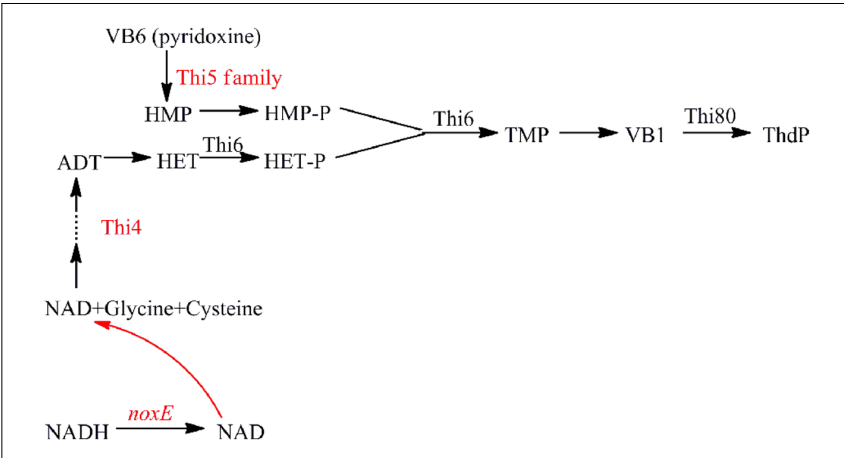

FIGURE 6 | Shematic representation of the ThdP synthesis pathway in S. cerevisiae showing the enzymes involved. ADT: adenosine diphospho-5-( $\beta$-ethyl)-4-methylthiazole-2-carboxylic acid; HET: 5-Hydroxyethyl-4-methylthiazole; HET-P: 5-Hydroxyethyl-4-methylthiazole phosphate; HMP: hydroxymethylpyrimidine; HMP-P: hydroxymethylpyrimidine phosphate; TMP: thiamine phosphate; Thi4: eukaryotic thiazole biosynthetic enzyme; Thi5 family: THI11, THI12, THI13, and THI5 genes; Thi6: encoding a bifunctional enzyme with both thiamine-phosphate pyrophosphorylase and HET kinase activities; Thi80: needed for both ThdP de novo synthesis and the conversion of external thiamine to ThdP. Genes upregulated in NOX vs. CON in the mid-exponential phase are indicated in red.

expression of the THI gene family was drastically elevated in the mid-exponential phase in NOX vs. CON [THI5: 4.72, THI11: 3.67, THI12: 2.97, and THI13: 2.95 (values are $\log _{2}$ ratios)]. Wightman and Meacock (2003) described that in the Saccharomyces sensu stricto group, yeasts have multiple copies of THI5, and a great many of the amplified genes in THI5overexpressing strains found near the telomeres, including those in duplicated THI5 blocks, encode proteins involved in sugar uptake and metabolism (e.g., HXT, SUC, MAL, etc.). These amplifications of sugar uptake genes probably confer rapid uptake mechanisms leading to a greater glycolytic flux to pyruvate. In accordance herewith, in our study, the expression of hexose transport genes HXT6 and HXT16 was significantly upregulated (6.97 and 3.01, respectively) in NOX at the midexponential phase. In batch fermentation, the glucose uptake of NOX was much faster than that of CON, and thiamine accelerated the cell growth in NOX, especially in the midexponential phase (Wolak et al., 2014). At the end of the exponential phase, the expression of the THI5 gene family did not significantly change in NOX. This could be explained by the fact that after $29.5 \mathrm{~h}$ of fermentation, the glucose in the NOX medium was exhausted and the fermentation completed; thus, less ThdP was needed as compared to the mid-exponential phase.

THI4 is a eukaryotic thiazole biosynthetic enzyme that catalyzes the conversion of ADT to HET, which was shown to protect cells against destabilizing conditions (Wolak et al., 2014). In our study, overexpression of the NADH oxidase regulated the intracellular redox balance by increasing the demand and oxidation of $\mathrm{NADH}$ as well as the regeneration of $\mathrm{NAD}^{+}$, likely improving the synthesis of thiazole (THI4: 4.27). However, unlike the THI5 gene family and the THI4 gene, the expression of downstream genes ThdP synthesis genes 
THI6 (encoding a bifunctional enzyme with both thiaminephosphate pyrophosphorylase and HET kinase activities) and THI80 (needed for both ThdP de novo synthesis and the conversion of external thiamine to ThdP; Mojzita and Hohmann, 2006) was not significantly changed, even at the mid-exponential phase. Similarly, the expression of genes encoding ThdP-dependent enzymes pyruvate decarboxylase and pyruvate dehydrogenase was not significantly changed. The positive regulator of ThdP, THI2 (Mojzita and Hohmann, 2006), was upregulated only at the end of the exponential phase. These results indicated that overexpression of the $\mathrm{NADH}$ oxidase could stimulate thiamine, involved in redox balance maintenance in yeast cells, partly independently of the functions of ThdP and ThdP-dependent enzymes (Wolak et al., 2014).

\section{Transcriptional Response of the Global Transcription Factor HAP4 to the NADH Oxidase Overexpression}

At the end of the exponential phase, the expression of HAP4 was remarkably increased (4.06) upon $\mathrm{NADH}$ oxidase overexpression. Previous studies found that HAP4 overexpression provokes changes that also occur during the diauxic shift-a type of starvation response (Blom et al., 2000; Lascaris et al., 2002). In our study, after $29.5 \mathrm{~h}$ of fermentation, residual glucose was almost undetectable in NOX culture and the cells had started to use the ethanol as indicated by the lowered concentration of ethanol at this time point, suggestive of a diauxic shift. Schuurmans et al. (2008) reported that overexpression of HAP4 in glucose-rich growth condition results in increased mitochondrial biogenesis. In addition, genes involved in oxidative phosphorylation were strongly upregulated. According to our transcriptome data, various genes involved in oxidative phosphorylation, such as YMR145C (encoding NADH dehydrogenase); COR1, QCR6, QCR7, and QCR8 in Complex III; and COX6A and COX15 (YER141W) in Complex IV, were significantly upregulated in NOX at the end of the exponential phase. Overexpression of HAP4 negatively affects the transcription of a small set of genes involved in zinc metabolism mediated through decreased expression of the transcription factor Zap1 (YJL056C; Lascaris et al., 2002). The motif bound by the Zap1 regulator, which controls zinc transport and homeostasis, was strongly downregulated, suggesting that there is a much lower demand for $\mathrm{Zn}$ in strains overexpressing HAP4 (Schuurmans et al., 2008). Our transcriptome data revealed that the expression of several genes involved in zinc metabolism [YGL258W (-1.04), SNO1 (-1.59), RTC4 $(-1.33)$ etc.] was reduced. The changes were much smaller than those reported by Schuurmans et al. (2008), who found that overexpression of HAP4 increased the expression of a high-affinity glucose transporter and significantly induced genes associated with growth on non-fermentable carbon sources (e.g., $A D H 2$ and FBP1). In our study, the high-affinity hexose transporter HXT6 (7.88) was significantly upregulated in NOX at the late-exponential phase. In accordance with a diauxic shift, the expression of FBP1 (2.12) was increased.

\section{Overexpression of the NADH Oxidase Regulates Apoptosis Related Genes}

Changes in redox homeostasis through the fermentation process would increase the accumulation of ROS (Ayer et al., 2014). $\mathrm{Xu}$ et al. (2010) found that overexpression of the water-forming NADH oxidase in T. glabrata decreased the ROS production, protecting the yeast cells from ROS damage. ROS are widely recognized as crucial cell death regulators and have been connected to many of the known apoptotic pathways in yeast. Carmona-Gutierrez et al. (2010) have comprehensively analyzed apoptosis in yeast. Since the discovery of yeast apoptosis, multiple yeast orthologs of crucial mammalian apoptotic proteins have been identified. Yeast bears at least one ortholog of mammalian caspases: the metacaspase Yca1. Numerous cell death scenarios have been shown to depend on Yca1. Apoptotic death mediated by the apoptosis-inducing factor Nuc1, the yeast homolog of endonuclease-G, does not require Ycal.

To determine whether the overexpression of noxE in $S$. cerevisiae could decrease ROS, ROS production by CON and NOX cells was evaluated (Figure 7). In both CON and NOX strains, ROS production was not significantly increased at $34 \mathrm{~h}$ as compared to $22 \mathrm{~h}$. The production of ROS was approximately $10 \%$ lower in NOX than in CON at both time points. This result was consistent with the results of Xu et al. (2010).

To analyze the effect of NADH oxidase overexpression on yeast apoptosis, we checked the expression levels of apoptosisrelated factors and proteins reported by Carmona-Gutierrez et al. (2010). We found that Nuc1 was downregulated at the midexponential phase $(-1.03)$ and at the end of exponential phase (-3.57). In addition, karyopherin Kap123, which is necessary for Nuc1-mediated apoptosis (Carmona-Gutierrez et al., 2010), was downregulated $(-1.29)$ at the end of the exponential phase. Similar to other apoptotic players, Nucl exerts lethal and vital functions as illustrated by deletion of the gene, which inhibits apoptosis when mitochondrial respiration is enhanced

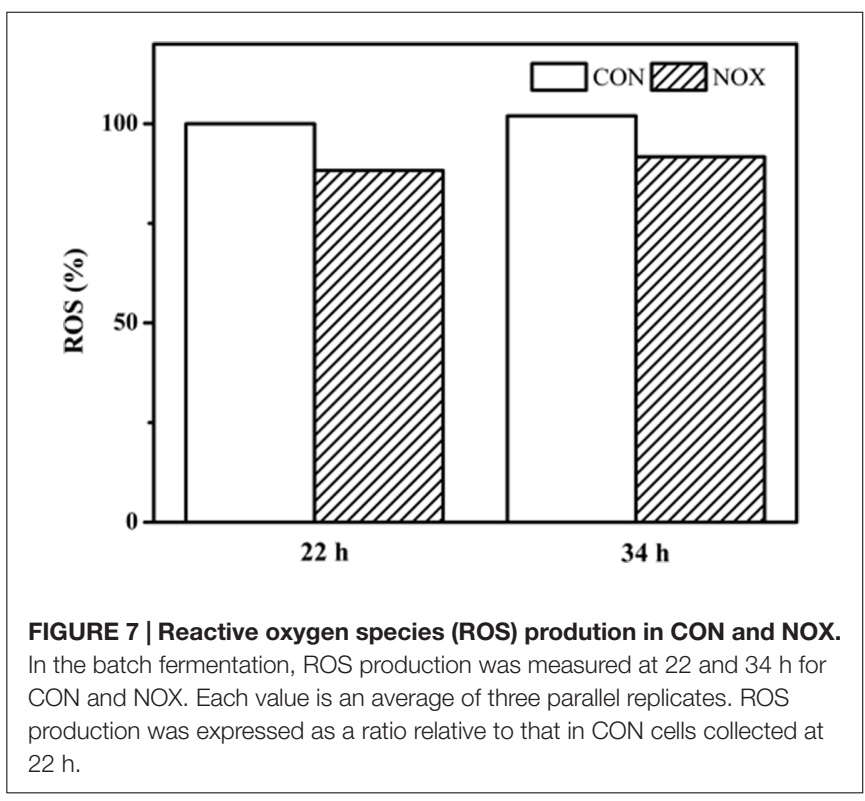


but increases necrotic death when oxidative phosphorylation is repressed (Ayer et al., 2014). As indicated by the HAP4 expression data mentioned above, the NOX cells might undergo a diauxic shift, which would enhance mitochondrial respiration, and in this condition, the downregulated Nuc1 might inhibit apoptosis. Büttner et al. (2007) also reported that at the beginning of the stationary phase, there is a Nuc1-dependent apoptotic clearance. The higher cell density of NOX compared to CON (Figure 1B) at the beginning of the stationary phase in our study supported this viewpoint.

In addition to ROS, the small signaling molecules $\mathrm{NO}$ and ammonia regulate yeast apoptosis. During the development of multicellular yeast colonies, ammonia accumulates in the center of the colonies and triggers the death of older cells, allowing young cells on the rim to exploit the released nutrients. Consistently, lack of the transcription factor Sok2, which results in the inability to produce ammonia, leads to diffuse death throughout the population and diminishes the life span of the colony (Carmona-Gutierrez et al., 2010). In the current study, the transcription factor Sok2 was upregulated at the end of the exponential phase (2.39).

In conclusion, overexpression of the NADH oxidase in S. cerevisiae regulated several apoptosis related genes. However, apoptosis was not induced on a large scale in our study, as evidenced by both cell growth and transcription; therefore, the detailed relationship between overexpression of NADH oxidase and yeast apoptosis could not be determined in this study and requires further research.

\section{Heterologous Expression of NADH Oxidase Enhances S. cerevisiae Growth under Hyperosmotic Stress}

It has been reported that the osmotolerance of $T$. glabrata cells can be enhanced by the introduction of water-forming $\mathrm{NADH}$ oxidase (Xu et al., 2010). To analyze the effect of the enzyme on osmotic stress in $S$. cerevisiae, we measured the osmolarity of the media of NOX and CON after $30 \mathrm{~h}$ of fermentation. The osmolarity of the fermentation medium of $\mathrm{CON}$ was $1834 \pm 6 \mathrm{mOsmol} / \mathrm{kg}$, while that of $\mathrm{NOX}$ was $2028 \pm 2 \mathrm{mOsmol} / \mathrm{kg}$, which was a $10.58 \%$ increase as compared to CON. Since NOX produced more ethanol than CON (Figure 1A), it is conceivable that the NOX strain was under higher osmotic stress.

The HOG MAPK pathway plays a role in the adaptation of yeast cells to high osmotic pressure (O’Rourke et al., 2002). Under continued activation of the HOG pathway in case of chronic osmotic stress, the cells die (Jiang et al., 2004). In Figure 8, the HOG pathway is superimposed on our transcriptome data. During the fermentation of NOX, the HOG pathway seemed not to be activated even at the end of the logarithmic phase, although the osmotic stress was truly higher than in CON. The low production of glycerol in NOX confirmed inactivity of the HOG pathway.

To further study the survival ability of NOX and CON under hyperosmotic stress, qualitative sensitivity at different concentrations of $\mathrm{NaCl}$ was measured as colony-forming units

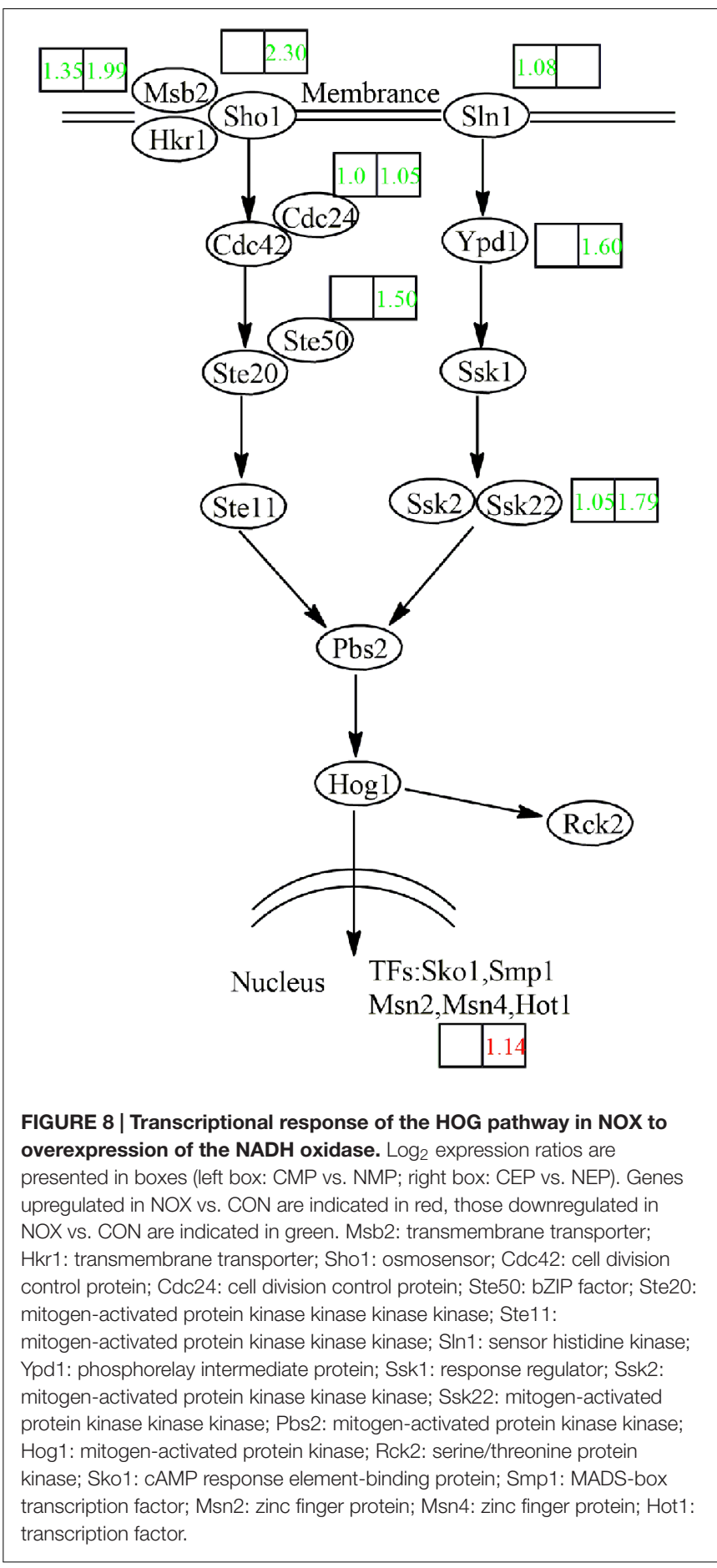

at different dilution levels (Figure 9; Xu et al., 2010). Organism suspensions were OD-standardized before sample application $(2 \mu \mathrm{L})$. After $48 \mathrm{~h}$, similar colonies of NOX and CON were observed at initial concentration in four plates (leftmost column in Figures 9A-D). However, the engineered NOX strain had a 10 -fold higher survival rate than $\mathrm{CON}$ at 0,9 , and $27 \mathrm{~g} / \mathrm{L}$ of $\mathrm{NaCl}$ (Figures 9A-C). Larger and more colonies of NOX were observed at $10^{-4}$ dilution and $45 \mathrm{~g} / \mathrm{L} \mathrm{NaCl}$ as compared to CON. 


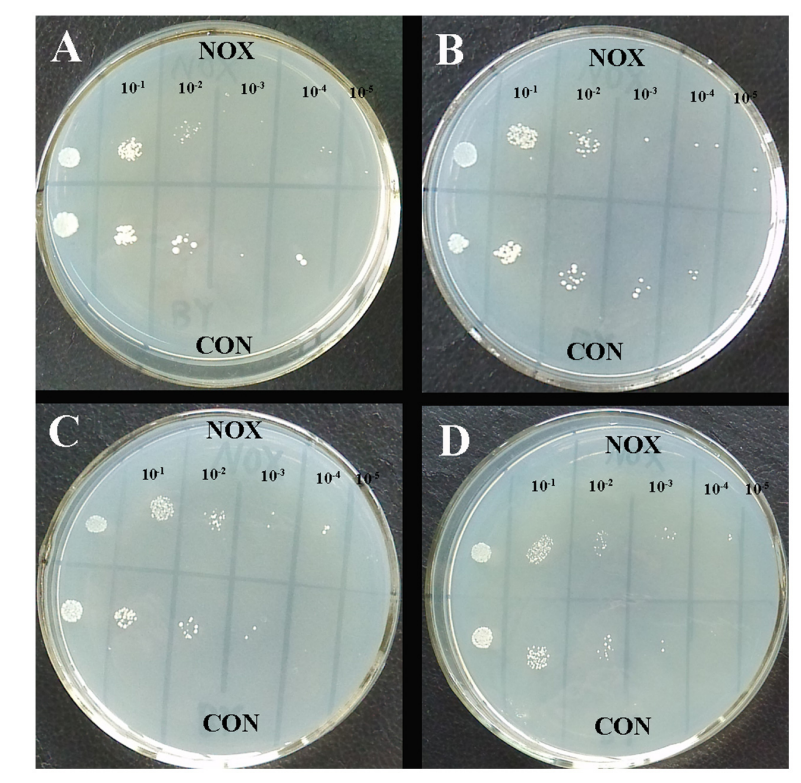

FIGURE 9 | Resistance of CON and NOX to osmotic stress. (A) $0 \mathrm{~g} / \mathrm{L}$ $\mathrm{NaCl}$; (B) $9 \mathrm{~g} / \mathrm{L} \mathrm{NaCl}$; (C) $27 \mathrm{~g} / \mathrm{L} \mathrm{NaCl}$; (D) $45 \mathrm{~g} / \mathrm{L} \mathrm{NaCl}$.

Similar results were reported by Xu et al. (2010) in T. glabrata. Our results suggested that heterologous expression of $\mathrm{NADH}$ oxidase in $S$. cerevisiae confers protection to $S$. cerevisiae under hyperosmotic conditions, which will reduce the cells death.

\section{Confirmation of Transcriptome Profiling Results by qRT-PCR}

The levels of transcription of various key genes mentioned above were verified by qRT-PCR (Figure 10). As shown in Figure 10B, noxE was not expressed in the control strain CON, and it was effectively expressed in the recombinant strain NOX. The expression levels of THI4 and HXT6 were significantly upregulated in NOX at $22 \mathrm{~h}$ (Figure 10A). The difference in HXT6 expression in NOX vs. CON was more pronounced at $30 \mathrm{~h}$ than at $22 \mathrm{~h}$. The expression of GUT1, involved in the glycerol assimilation pathway, was upregulated, whereas GPD1, involved in the glycerol synthesis pathway, was not differentially regulated. With respect to HOG pathway, the expression levels of Hogl and msn4 (a transcription factor) were not significantly changed, in accordance with the RNA-seq results. With regard to yeast apoptosis, the expression of Nucl was downregulated and the expression of Sok2 was upregulated in the NADH oxidase-overexpressing strain. Detailed results and calculations are presented in Additional file 7. The results of qRT-PCR indicated that the RNA-seq results are accurate and reliable, strengthening our conclusions from these data.

\section{CONCLUSION}

This study unraveled the response S. cerevisiae to overexpression of a water-forming $\mathrm{NADH}$ oxidase at the metabolic and the
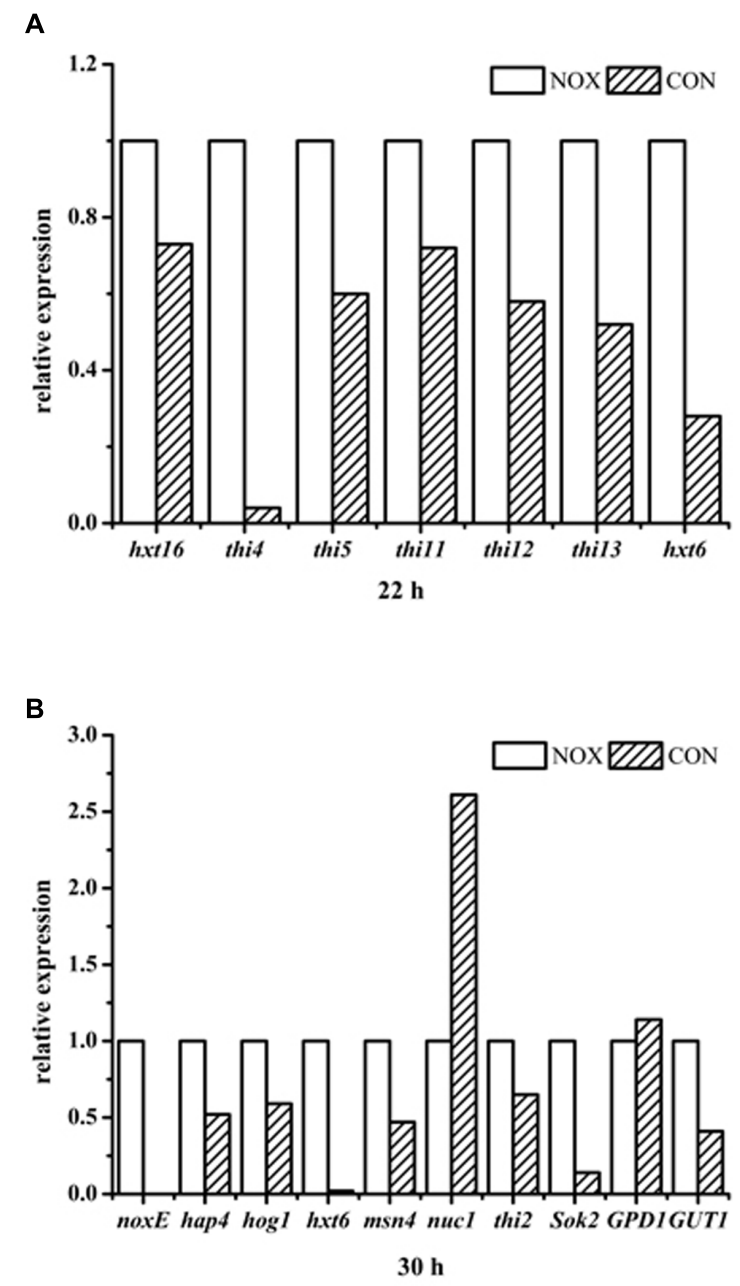

FIGURE 10 | qRT-PCR results. (A) relative expression of genes in NOX vs. CON after 22 h of fermentation; (B) relative expression of genes in NOX vs. CON after $30 \mathrm{~h}$ of fermentation.

transcriptional level. In batch fermentation, we observed reduced glycerol and increased glucose consumption, ethanol, and cell growth in the NOX strain, showing the potential usability of the recombinant $S$. cerevisiae strain in large-scale ethanol production. In addition, overexpression of the $\mathrm{NADH}$ oxidase conferred protection to $S$. cerevisiae under hyperosmotic conditions. The expression of multiple genes was changed at the three time points evaluated. Compared with $\mathrm{CON}$, various genes related to thiamine synthesis were upregulated during NOX fermentation. After $29.5 \mathrm{~h}$ of fermentation, the glucose in NOX culture was almost exhausted and the strain underwent a diauxic shift, with significant upregulation of the global transcriptional factor HAP4. The heterologous expression of NADH oxidase in $S$. cerevisiae lowered the ROS production. The yeast apoptosisinducing factor Nuc1 was downregulated and transcription factor Sok2 was upregulated, collectively suggestive of the inhibition of apoptosis in the NOX strain. Thiamine plays an important role in the maintenance of redox balance, which is essential to 
sustain metabolism and growth. We reason that the upregulation of HAP4 resulted in enhanced mitochondrial respiration, which is essential for the downregulation of Nuc1 to inhibit apoptosis. In addition, because of the improved osmotolerance, the HOG pathway, which might be connected to Nucl-induced apoptosis, was not activated. Together, these transcriptional changes in response to stresses under the overexpression of $\mathrm{NADH}$ oxidase improved the metabolism and growth of $S$. cerevisiae cells under the given conditions. This study put forward possible relationships between the water-forming $\mathrm{NADH}$ oxidase and thiamine synthesis, the global transcriptional factor HAP4, apoptosis, and osmotolerance, providing several new directions for further study of the $\mathrm{NADH}$ oxidase and the molecular mechanism underlying the transcriptional changes.

\section{AUTHOR CONTRIBUTIONS}

XS participated in the design of the study, constructed the plasmids and strains, participated in the experiments, analyzed the RNA-seq data, drafted the manuscript, and revised the manuscript. YZ participated in the fermentation experiments. YC participated in the design of the study. CZ helped to analyze the data and revise the manuscript. HY conceived of the study, and participated in its design. All authors have read and approved the final manuscript.

\section{FUNDING}

This work was supported by the National High-Tech Research and Development Program of China (863) (2012AA021203), the National Basic Research Program of China (973)

\section{REFERENCES}

Alff-Tuomala, S., Salusjärvi, L., Barth, D., Oja, M., Penttila, M., Pitkänen, J. P., et al. (2016). Xylose-induced dynamic effects on metabolism and gene expression in engineered Saccharomyces cerevisiae in anaerobic glucose-xylose cultures. Appl. Microbiol. Biotechnol. 100, 969-985. doi: 10.1007/s00253-015-7038-7

Ayer, A., Gourlay, C. W., and Dawes, I. W. (2014). Cellular redox homeostasis, reactive oxygen species and replicative ageing in Saccharomyces cerevisiae. FEMS Yeast Res. 14, 60-72. doi: 10.1111/1567-1364.12114

Barber, A. R., Vriesekoop, F., and Pamment, N. B. (2002). Effects of acetaldehyde on Saccharomyces cerevisiae exposed to a range of chemical and environmental stresses. Enzyme Microb. Technol. 30, 240-250. doi: 10.1016/S0141-0229(01)00489-6

Benjamini, Y., and Yekutieli, D. (2001). The control of the false discovery rate in multiple testing under dependency. Ann. Stat. 29, 1165-1188.

Blom, J., De Mattos, M. J. T., and Grivell, L. A. (2000). Redirection of the respirofermentative flux distribution in Saccharomyces cerevisiae by overexpression of the transcription factor Hap4p. Appl. Environ. Microb. 66, 1970-1973. doi: 10.1128/AEM.66.5.1970-1973.2000

Büttner, S., Eisenberg, T., Carmona-Gutierrez, D., Ruli, D., Knauer, H., Ruckenstuhl, C., et al. (2007). Endonuclease G regulates budding yeast life and death. Mol. Cell 25, 233-246. doi: 10.1016/j.molcel.2006.12.021

Cao, Y. Y., Cao, Y. B., Xu, Z., Ying, K., Li, Y., Xie, Y., et al. (2005). cDNA microarray analysis of differential gene expression in Candida albicans biofilm exposed to farnesol. Antimicrob. Agents Chemother. 49, 584-589. doi: 10.1128/AAC.49.2.584-589.2005
(2013CB733602), the Major Research Plan of the National Natural Science Foundation of China (21390204), The National Technology Support Program (2012BAI44G01), the National Natural Science Foundation of China, General Program (21376118), the Program for Changjiang Scholars and Innovative Research Team in University (IRT_14R28), and the Priority Academic Program Development of Jiangsu Higher Education Institutions (PAPD).

\section{ACKNOWLEDGMENT}

We thank Yingjin Yuan for providing plasmid pYX212 and S. cerevisiae BY4741.

\section{SUPPLEMENTARY MATERIAL}

The Supplementary Material for this article can be found online at: http://journal.frontiersin.org/article/10.3389/fmicb. 2016.01427

ADDITIONAL FILE S1 | Gene ontology (GO) enrichment analysis for CBP and NBP cells.

ADDITIONAL FILE S2 | Gene ontology enrichment analysis for CMP and NMP cells.

ADDITIONAL FILE S3 | Gene ontology enrichment analysis for CEP and NEP cells.

ADDITIONAL FILE S4 | KEGG pathway analysis for CBP and NBP cells.

ADDITIONAL FILE S5 | KEGG pathway analysis for CMP and NMP cells.

ADDITIONAL FILE S6 | KEGG pathway analysis for CEP and NEP cells.

ADDITIONAL FILE S7 | Results of qRT-PCR of S. cerevisiae.

Carmona-Gutierrez, D., Eisenberg, T., Büttner, S., Meisinger, C., Kroemer, G., and Madeo, F. (2010). Apoptosis in yeast: triggers, pathways, subroutines. Cell Death Differ. 17, 763-773. doi: 10.1038/cdd.2009.219

Celton, M., Sanchez, I., Goelzer, A., Fromion, V., Camarasa, C., and Dequin, S. (2012). A comparative transcriptomic, fluxomic and metabolomic analysis of the response of Saccharomyces cerevisiae to increases in NADPH oxidation. BMC Genomics 13:317. doi: 10.1186/1471-2164-13-317

Chatterjee, A., Jurgenson, C. T., Schroeder, F. C., Ealick, S. E., and Begley, T. P. (2007). Biosynthesis of thiamin thiazole in eukaryotes: conversion of NAD to an advanced intermediate. J. Am. Chem. Soc. 129, 2914-2922. doi: 10.1021/ja067606t

Chen, Y., Ren, H. F., Liu, D., Zhao, T., Shi, X. C., Cheng, H., et al. (2014). Enhancement of n-butanol production by in situ butanol removal using permeating-heating-gas stripping in acetone-butanol-ethanol fermentation. Bioresour. Technol. 164, 276-284. doi: 10.1016/j.biortech.2014. 04.107

Doerks, T., Copley, R. R., Schultz, J., Ponting, C. P., and Bork, P. (2002). Systematic identification of novel protein domain families associated with nuclear functions. Genome Res. 12, 47-56. doi: 10.1101/gr.234503

Faou, P., and Tropschug, M. (2004). Neurospora crassa CyPBP37: a cytosolic stress protein that is able to replace yeast Thi4p function in the synthesis of vitamin B1. J. Mol. Biol. 344, 1147-1157. doi: 10.1016/j.jmb.2004.09.097

Heux, S., Cachon, R., and Dequin, S. (2006). Cofactor engineering in Saccharomyces cerevisiae: expression of a $\mathrm{H} 2 \mathrm{O}-$ forming $\mathrm{NADH}$ oxidase and impact on redox metabolism. Metab. Eng. 8, 303-314. doi: 10.1016/j.ymben.2005.12.003 
Hohmann, S., and Meacock, P. A. (1998). Thiamin metabolism and thiamin diphosphate-dependent enzymes in the yeast Saccharomyces cerevisiae genetic regulation. BBA Protein Struct. 1385, 201-219.

Holm, A. K., Blank, L. M., Oldiges, M., Schmid, A., Solem, C., Jensen, P. R., et al. (2010). Metabolic and transcriptional response to cofactor perturbations in Escherichia coli. J. Biol. Chem. 285, 17498-17506. doi: 10.1074/jbc.M109.095570

Hou, J., Lages, N. F., Oldiges, M., and Vemuri, G. N. (2009). Metabolic impact of redox cofactor perturbations in Saccharomyces cerevisiae. Metab. Eng. 11, 253-261. doi: 10.1016/j.ymben.2009.05.001

Hou, J., Scalcinati, G., Oldiges, M., and Vemuri, G. N. (2010). Metabolic impact of increased NADH availability in Saccharomyces cerevisiae. Appl. Environ. Microb. 76, 851-859. doi: 10.1128/AEM.02040-09

Hou, J., Suo, F., Wang, C. Q., Li, X. W., Shen, Y., and Bao X. M. (2014). Finetuning of NADH oxidase decreases byproduct accumulation in respiration deficient xylose metabolic Saccharomyces cerevisiae. BMC Biotechnol. 14:13. doi: 10.1186/1472-6750-14-13

Irie, N., and Kuratani, S. (2011). Comparative transcriptome analysis reveals vertebrate phylotypic period during organogenesis. Nat. Commun. 2:248. doi: $10.1038 /$ ncomms 1248

Ito, H., Fukuda, Y., Murata, K., and Kimura, A. (1983). Transformation of intact yeast cells treated with alkali cations. J. Bacteriol. 153, 163-168.

Jeong, H., Tombor, B., Albert, R., Oltvai, Z. N., and Barabási, A. L. (2000). The large-scale organization of metabolic networks. Nature 407, 651-654. doi: $10.1038 / 35036627$

Jiang, L., Niu, S., Clines, K. L., Burke, D. J., and Sturgill, T. W. (2004). Analyses of the effects of Rck2p mutants on Pbs2pDD-induced toxicity in Saccharomyces cerevisiae identify a MAP kinase docking motif, and unexpected functional inactivation due to acidic substitution of T379. Mol. Genet. Genomics 271, 208-219. doi: 10.1007/s00438-003-0972-6

Jurgenson, C. T., Chatterjee, A., Begley, T. P., and Ealick, S. E. (2006). Structural insights into the function of the thiamin biosynthetic enzyme Thi4 from Saccharomyces cerevisiae. Biochemistry 45, 11061-11070. doi: 10.1021/bi061025z

Kim, J. W., Seo, S. O., Zhang, G. C., Jin, Y. S., and Seo, J. H. (2015). Expression of Lactococcus lactis NADH oxidase increases 2,3-butanediol production in Pdc-deficient Saccharomyces cerevisiae. Bioresour. Technol. 191, 512-519. doi: 10.1016/j.biortech.2015.02.077

Lascaris, R., Bussemaker, H. J., Boorsma, A., Piper, M., van der Spek, H., Grivell, L., et al. (2002). Hap4p overexpression in glucose-grown Saccharomyces cerevisiae induces cells to enter a novel metabolic state. Genome Biol. 4:R3. doi: 10.1186/gb-2002-4-1-r3

Lee, S. H., Kodaki, T., Park, Y. C., and Seo, J. H. (2012). Effects of NADHpreferring xylose reductase expression on ethanol production from xylose in xylose-metabolizing recombinant Saccharomyces cerevisiae. J. Biotechnol. 158, 184-191. doi: 10.1016/j.jbiotec.2011.06.005

Li, Z. J., Chen, Y., Liu, D., Zhao, N., Cheng, H., Ren, H. F., et al. (2015). Involvement of glycolysis/gluconeogenesis and signaling regulatory pathways in Saccharomyces cerevisiae biofilms during fermentation. Front. Microbiol. 6:139. doi: 10.3389/fmicb.2015.00139

Liu, D., Chen, Y., Li, A., Ding, F. Y., Zhou, T., He, Y., et al. (2013). Enhanced butanol production by modulation of electron flow in Clostridium acetobutylicum B3 immobilized by surface adsorption. Bioresour. Technol. 129, 321-328. doi: 10.1016/j.biortech.2012.11.090

Liu, W., and Wang, P. (2007). Cofactor regeneration for sustainable enzymatic biosynthesis. Biotechnol. Adv. 25, 369-384. doi: 10.1016/j.biotechadv.2007.03.002
Mojzita, D., and Hohmann, S. (2006). Pdc2 coordinates expression of the THI regulon in the yeast Saccharomyces cerevisiae. Mol. Genet. Genom. 276, 147-161. doi: 10.1007/s00438-0060130-Z

Monk, J. M., Charusanti, P., Aziz, R. K., Lerman, J. A., Premyodhin, N., Orth, J. D., et al. (2013). Genome-scale metabolic reconstructions of multiple Escherichia coli strains highlight strain-specific adaptations to nutritional environments. Proc. Natl. Acad. Sci. U.S.A. 110, 20338-20343. doi: 10.1073/pnas. 1307797110

Nielsen, J. (2003). It is all about metabolic fluxes. J. Bacteriol. 185, 7031-7035. doi: 10.1128/jb.185.24.7031-7035.2003

O’Rourke, S. M., Herskowitz, I., and O'Shea, E. K. (2002). Yeast go the whole HOG for the hyperosmotic response. Trends Genet. 18, 405-412. doi: 10.1016/S01689525(02)02723-3

Schuurmans, J. M., Boorsma, A., Lascaris, R., Hellingwerf, K. J., and Teixeira de Mattos, M. J. (2008). Physiological and transcriptional characterization of Saccharomyces cerevisiae strains with modified expression of catabolic regulators. FEMS Yeast Res. 8, 26-34. doi: 10.1111/j.1567-1364.2007. 00309.x

Shi, X. C., Zou, Y. N., Chen, Y., Zheng, C., Li, B. B., Xu, J. H., et al. (2016). A waterforming $\mathrm{NADH}$ oxidase regulates metabolism in anaerobic fermentation. Biotechnol. Biofuels 9:103. doi: 10.1186/s13068-016-0517-y

Stephanopoulos, G. (1999). Metabolic fluxes and metabolic engineering. Metab. Eng. 1, 1-11. doi: 10.1006/mben.1998.0101

Vemuri, G. N., Eiteman, M. A., McEwen, J. E., Olsson, L., and Nielsen, J. (2007). Increasing NADH oxidation reduces overflow metabolism in Saccharomyces cerevisiae. Proc. Natl. Acad. Sci. U.S.A. 104, 2402-2407. doi: $10.1073 /$ pnas.0607469104

Wightman, R., and Meacock, A. P. (2003). The THI5 gene family of Saccharomyces cerevisiae: distribution of homologues among the hemiascomycetes and functional redundancy in the aerobic biosynthesis of thiamin from pyridoxine. Microbiology 149, 1447-1460. doi: 10.1099/mic.0. 26194-0

Wolak, N., Kowalska, E., Kozik, A., and Rapala-Kozik, M. (2014). Thiamine increases the resistance of baker's yeast Saccharomyces cerevisiae against oxidative, osmotic and thermal stress, through mechanisms partly independent of thiamine diphosphate-bound enzymes. FEMS Yeast Res. 14, 1249-1262. doi: 10.1111/1567-1364.12218

Xu, S., Zhou, J., Qin, Y., Liu, L., and Chen, J. (2010). Water-forming NADH oxidase protects Torulopsis glabrata against hyperosmotic stress. Yeast 27, 207-216. doi: 10.1002/yea. 1745

Yuan, J., and Ching, C. B. (2015). Dynamic control of ERG9 expression for improved amorpha-4,11-diene production in Saccharomyces cerevisiae. Microb. Cell Fact. 14:38. doi: 10.1186/s12934-015-0220-x

Zhao, H., and van der Donk, W. A. (2003). Regeneration of cofactors for use in biocatalysis. Curr. Opin. Biotechnol. 14, 583-589. doi: 10.1016/j.copbio.2003.09.007

Conflict of Interest Statement: The authors declare that the research was conducted in the absence of any commercial or financial relationships that could be construed as a potential conflict of interest.

Copyright (C) 2016 Shi, Zou, Chen, Zheng and Ying. This is an open-access article distributed under the terms of the Creative Commons Attribution License (CC BY). The use, distribution or reproduction in other forums is permitted, provided the original author(s) or licensor are credited and that the original publication in this journal is cited, in accordance with accepted academic practice. No use, distribution or reproduction is permitted which does not comply with these terms. 